OPEN ACCES

\title{
Activated Carbon Nanoparticles As Carriers of Anticancer Drugs
}

\author{
Lan Sun ${ }^{1}$, Yaoxin $\mathrm{Cai}^{2}$, Yanlei Liu ${ }^{1}$, Dongying Song ${ }^{3}$, Yan Liu ${ }^{1}$, Hongjuan Yao ${ }^{1}$, Yingge Zhang ${ }^{1 *}$ \\ ${ }^{1}$ Institute of Pharmacology and Toxicology, Academy of Military Medical Sciences, Beijing100850, China \\ ${ }^{2}$ Department of Pharmacy, Chinese PLA General Hospital, Beijing100853, China \\ ${ }^{3}$ Jilin University, Changchun 130021, China \\ *Corresponding author: Yingge Zhang (Zhangyg58@126.com)
}

\begin{abstract}
The potentials of activated carbon nanoparticles (ACNP) as anticancer drug carriers were studied. ACNP were prepared with a top-down method. ACNP-based drug delivery system of docetaxel (ACNP-DOC) was prepared with a simple absorption method and its effects were studied primarily with methyl thiazolyl tetrazolium (MTT) assay, light microscope (LM), atomic force microscope (AFM) and transmission electron microscope (TEM). The prepared ACNP were approximately globular in shape with an average size of $233 \mathrm{~nm}$, which had a saturate adsorption of $195.69 \mathrm{mg} / \mathrm{g}$ at mass ratio of ACNP: DOC=5:1. The drug delivery system prepared by adsorbing of ACNP for DOC had excellent releasing profile in the simulated in vivo environment. LM observation showed that ACNP can accumulate around the cells and on the surface of cells and TEM revealed that ACNP can enter cells and nuclears. MTT test demonstrated that ACNP-DOC had inhibitive effects on the growth of A549 cells, with an IC50 of $0.79 \mu \mathrm{g} / \mathrm{ml}$, significantly smaller than that of $20 \mu \mathrm{g} / \mathrm{ml}$ of free DOC, indicating ACNP-DOC had stronger effects than free DOC. The imaging of AFM showed that both DOC and ACNP-DOC caused significant pathological changes of the cell membrane, including rough surfaces, large grains and holes, but these pathological changes were more obvious in ACNP-DOC treated cells than those free DOC treated ones. In all of the experiments, ACNP themselves had no significant influences on A549 cells. It was concluded that ACNP could serve as a good nanocarrier for anti-cancer drug delivery to target cells and have a great potential application in antitumor chemotherapy.
\end{abstract}

Keywords: Activated carbon nanoparticles, Atomic force microscopy, A549 cells, Docetaxel

Citation: L. Sun et al. Activated Carbon Nanoparticles As Carriers of Anticancer Drugs. Nano Biomed. Eng. 2013, 35(2), 94-101. DOI: 10.5101/nbe.v3i1.p94-101.

\section{Introduction}

Activated carbon (AC) is chemically composed of disordered graphite sheets with broad and strong absorption properties for chemical substances, which makes them very suitable for being used as drug carriers and therefore AC particles (ACPs) have been used as anticancer drug carriers for target chemotherapies. However, the effects of ACPs as drug carriers were influenced by many factors, including their morphology and sizes. The traditional ACPs have larger sizes and irregular morphology with weak targeting therapeutic effects and some serious complications such as the stimulating to abdominal tissues and the adherence of tissues so that their clinical use has been greatly limited. The advent into being of nanotechnology has brought an opportunity to improve their morphology and reduce their sizes and thereby to obtain satisfactory therapeutic effects. Activated carbon nanoparticles (ACNPs) are nanosized ACPs with spherical morphology, relatively smooth surfaces, stronger absorption, better lymph taxis and excellent targeting effects to cancer focuses, and have been used as tracer of drainage lymph node to help the section surgery of stomach cancers and drug carriers clinically to treat and prevent the lymph metastasis of cancers [1-5].

In recent years, our research group has deeply investigated the therapeutic effects of ACNPs used as anti-cancer drug carriers on experimental cancers. Compared with regular preparations, the anti-cancer drug delivery systems based on ACNPs have shown significant advantages over other drug delivery systems [6]. For example, ACNP-based drug delivery systems can control the drug concentration around particles that can be accurately calculated by mathematical equations, making it possible to keep the drug concentration in the lymphatic system well above the level to kill tumor cells below the level to harm the normal cells $[7,8]$. At the same time, ACNPbased drug delivery systems demonstrated to have rather strict lymph targeting effects. When intraperitonealy injected, ACNPs nearly completely distribute in lymph or lymphoid tissues and can never be seen in other tissues. Because of the excellently controlled releasing and lymph targeting effects, $50 \%$ radical treatment of the implanted stomach cancers can be achieved and more than $90 \%$ 
metastasis can be prevented by intraperitoneal injection of ACNP-based drug delivery systems. DOC is a new type of agent to act on microtubules, which can stabilize the microtubules by promoting the polymerization of monomers and preventing the depolymerization of microtubule protein dimmers. Thus, DOC suppresses normal dynamic restructuring of cell's micro pipe network during period of interphase and mitotic phase. Furthermore, DOC can lead to abnormal tiny tube "bundle" and influence the decomposition of tumor cells in the period of cell cycle or mitosis, producing multiple star. According to the above antitumor mechanism, DOC can play cancer-fighting properties based on DOC entering into or interacting with the skeleton of tumor cells. Many researches on nano-drug delivery systems have shown that nanocarriers can improve the effects of anti-cancer drugs, such as carbon nanotubes, one kind of nanocarriers, that can improve the effects of paclitaxel, gene and cisplatin, small molecules to kill cancer cells [912].The mechanism of nanocarriers worked because of it can carry drugs to enter into the cells through something like a "nano needle" or the endocytosis $[13,14]$. ACNPs are a kind of new nanocarriers, but there is still no reports on the effects of anti-cancer drug delivery systems based on ACNPs. In the present paper, the delivery systems with ACNPs as anticancer drug carriers are made to study the restraint to cancer cell using person's A549 lung cancer cells.

\section{Methods}

\subsection{Preparation of ACNP}

At present, there are many different specifications of activated carbon particles in market, and their diameter, form and specific surface area are different from each other. Our lab adopts sedimentation method to get ACNPs with uniform diameters and form. Activated carbon particles were bought from market and reground in a pulverisette 7 planetary micro mill premium line to obtain a mixture of activated carbon particles with various diameters. These activated carbon particle mixtures were suspended in distilled water in a concentration of $2 \mathrm{~g} / \mathrm{L}$ under stirring. The prepared suspension (S1) was allowed to standstill for some days. The larger particles had a larger sedimentation velocity because of their larger sedimentation coefficient so that the particles participated in an order of from larger to smaller. After 5 days, the suspension in the top $10 \mathrm{~cm}$ was taken out and was filtrated with a filter with certain diameter pores. The particles that can't leach through the pores were accumulated on the filter and were collected. The collected particles were re-suspended in triply-distilled water (S2). S2 was put into $15 \mathrm{ml}$ glass Ampoules, which was placed in $\mathrm{a}-80^{\circ} \mathrm{C}$ refrigerator for freeze drying. After $24 \mathrm{~h}$ freeze-drying a kind of black powder was obtained. For characterization, the particles of the powder were resuspended in triply-distilled water again (S3), which was dropped onto the cupper mesh for TEM or onto fresh mica surface for AFM observation.

\subsection{The preparation of ACNP-DOC drug delivery system (ACNP-DOC)}

DOC was firstly dissolved in a solution composed of 1:1 cremephor EL and ethanol in a concentration of $5 \mathrm{mg} / \mathrm{ml}$. ACNP was suspended in pure ethanol. ACNP suspension and DOC solution were blended in a certain proportion. The mixture was placed in an ultrasound field of $40 \mathrm{~Hz}$, $300 \mathrm{~W}$ for $30 \mathrm{~min}$ to allow DOC sufficiently to enter the micropores of ACNP and then was allowed to standstill for $20 \mathrm{~min}$. The adsorption of ACNP for DOC was achieved by the self assembling of DOC on the surface of the micropores of ACNP at a temperature of $25^{\circ} \mathrm{C}$. The quantity of DOC absorbed by ACNP was detected with UV spectrometry at different time spot. The time when the amount of the DOC reached to the highest was treated as the equilibrium point. Changing proportions of ACNP with DOC, the best adsorption can be achieved. The best ratio of ACNP and DOC was determined based on the isothermal adsorption formula. With a constant temperature wave bed, a dialysis device and a simulated drug-releasing environment in vivo, the releasing profile of DOC by ACNP was studied.

\subsection{Cell lines and cell culture}

Human A549 cell line from cell Resource Center of Institute of Basic Medical Science, Chinese Academy of Medical Science, Beijing, China were regularly cultured in Dulbecco's Modified Eagle Medium(DMEM) supplemented with $10 \%$ fetal bovine serum(FBS) (Gibco, Invitrogen, California) at $37^{\circ} \mathrm{C}$ in a humidified atmosphere of $95 \%$ oxygen and $5 \%$ carbon dioxide. The same culture conditions were provided for both the control and the experimental groups.

\subsection{Drug treatment of the cells}

DOC was dissolved in ethanol. ACNP and ACNPDOC were respectively suspended in PBS. ACNP, DOC and ACNP-DOC suspension were respectively added into the medium for the logarithmic phase cells. The final concentration of ACNP and DOC were respectively $0.8 \sim 500$ and $0.16 \sim 100 \mu \mathrm{g} / \mathrm{ml}$. The concentration of ACNP-DOC was calculated in the concentration of DOC. Normal saline was used as blank control and free DOC was used as positive control. After the addition of the above drugs, the cells were further cultivated for a certain period for different detection.

\subsection{The observation of the behavior of ACNP in culture medium}

The behavior of ACNP in the medium may be directly observed under light microscope (LM). In brief, after the addition of drugs, cells were further cultivated for $24 \mathrm{~h}$. The culture dish was placed under an inverse phase LM (Olympus, Japan) to observe.

\subsection{The subcellular distribution of ACNP in cells observed under TEM.}

Cultured A549 cells were washed with phosphate 
http://nanobe.org

buffer solutions for three times and fixed in $2.5 \%$ glutaraldehyde for $1 \mathrm{~h}$ and then in osmium tetraoxide for $1 \mathrm{~h}$ at $4^{\circ} \mathrm{C}$. The fixed samples were dehydrogenated serially in ethanol and embedded in Epon 812. 75 80 nm sections were made and observed under a Philips CM120 transmission electron microscope (TEM).

\subsection{AFM observation of the effect of ACNP-DOC on A549 Cells}

For AFM imaging, cells were fixed for $15 \mathrm{~min}$ in $2.5 \%$ glutaraldehyde. The fixed cells were washed by flowing triply distilled water to remove the crystals of the salts on the surface, which assured that the fine structure of cultured A549 cells were not covered. The short time washing of cultured A549 cells in triply distilled water did not damage the cells, since they had been fixed. Measurements were performed in the tapping mode in air using a silicon probe by a JPK Nanowithered I AFM (German) equipped with a scanner $(100 \times 100 \mu \mathrm{m})$. The sample was mounted onto the XY stage and was located to the regions of interest. To minimize the damage of the AFM tip to the morphology and structure of the A549 cell, the force and scanning frequency were initially adjusted to as small as possible. Commercially available silicon nitride cantilevers (Veeco InstrumentsCo. Ltd, USA) with a spring constant of about $42 \mathrm{~N} / \mathrm{m}$ and a scanning rate of 0.5-1.0 Hz were used. Image processing and data analysis were performed using SPM Version 3.3.25 Image Processing V.3 Off-line Software equipped with the instrument.

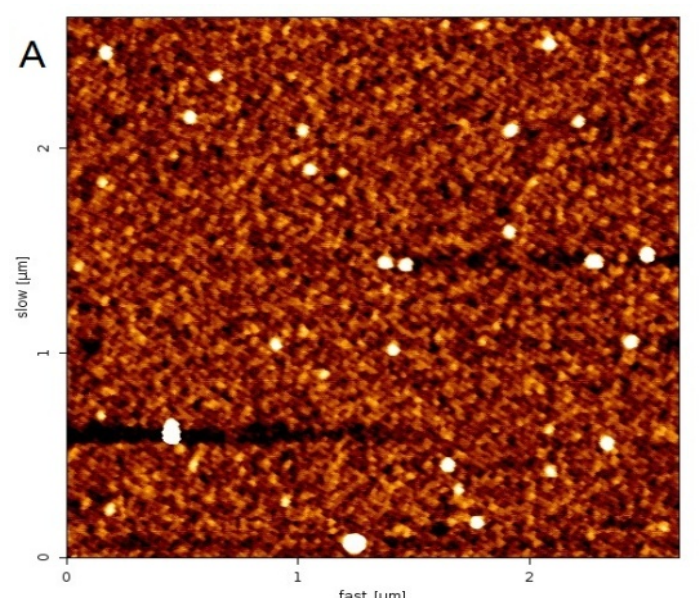

\subsection{Methyl thiazolyl tetrazolium (MTT) assay}

MTT dye in solution can be taken up by cells. In mitochondria, MTT was reduced to purple formazan which forms crystals, which accumulated within the living cells. The damage of cells results in the liberation of the purple product, which can be detected using colorimetric measurement. The ability of cells to reduce MTT provides an indication of the mitochondrial integrity and activity, which, in turn, may be interpreted as a measure of the cell number/proliferation/viability/survival/toxicity. Formazan crystals have highest absorption at $490 \mathrm{~nm}$, OD values were therefore measured at $490 \mathrm{~nm}$ using enzyme mark instrument (Thermo Scientific, USA).

\section{Results}

\subsection{ACNP and ACNP-DOC}

The AFM and TEM images show that the ACNP prepared by the ball-milling-precipitation method has regular morphology, with uniform particle size, smoother surface and approximate globular shape Fig. 1 (A, B). The average particle size was $233 \mathrm{~nm}$ as measured by laser particle size analyzer (Fig. 1C). In the concentration range of $1 \sim 8 \mathrm{mg} / \mathrm{L}$, the absorbance $\mathrm{D}$ of DOC and the concentration $\mathrm{C}$ of DOC had a linear positive correlation, satisfying the linear regression equation $\mathrm{D}=0.00412+$ $0.06429 \mathrm{C}(\mathrm{r}=0.99952, \mathrm{P}<0.0001)$ ( Fig. $2 \mathrm{~A})$. At $20^{\circ} \mathrm{C}$, ACNP reached to the balance state of absorbing DOC about $25 \mathrm{~min}$ later and there was no obvious change of DOC adsorption with the extension of time (Fig. 2B).

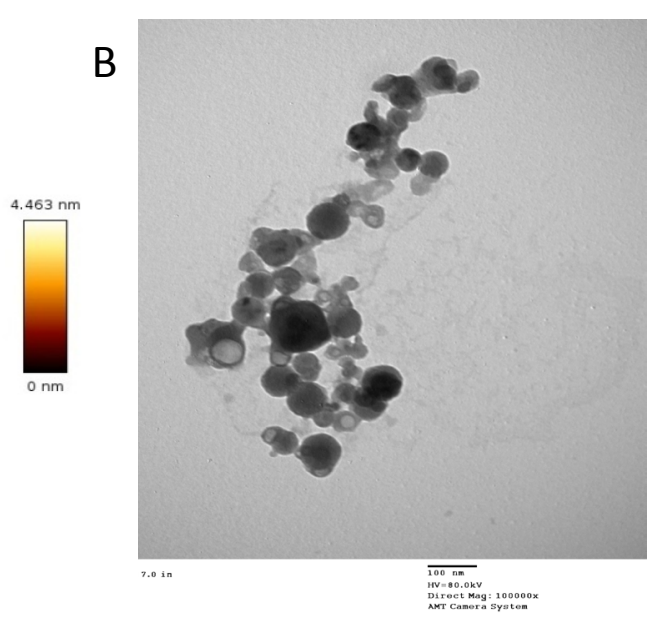

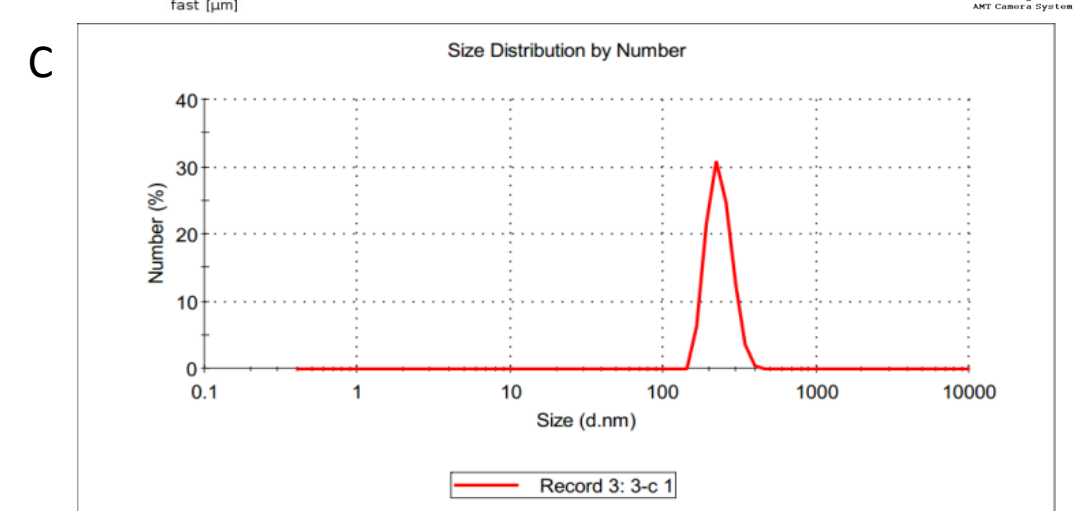

Fig. 1 Characterization of ACNPs by AFM, TEM and laser particle size analyzer. A: AFM Image of ACNPs; B: TEM Image of ACNPs; C: Size distribution of ACNPs by laser particle size analyzer. 

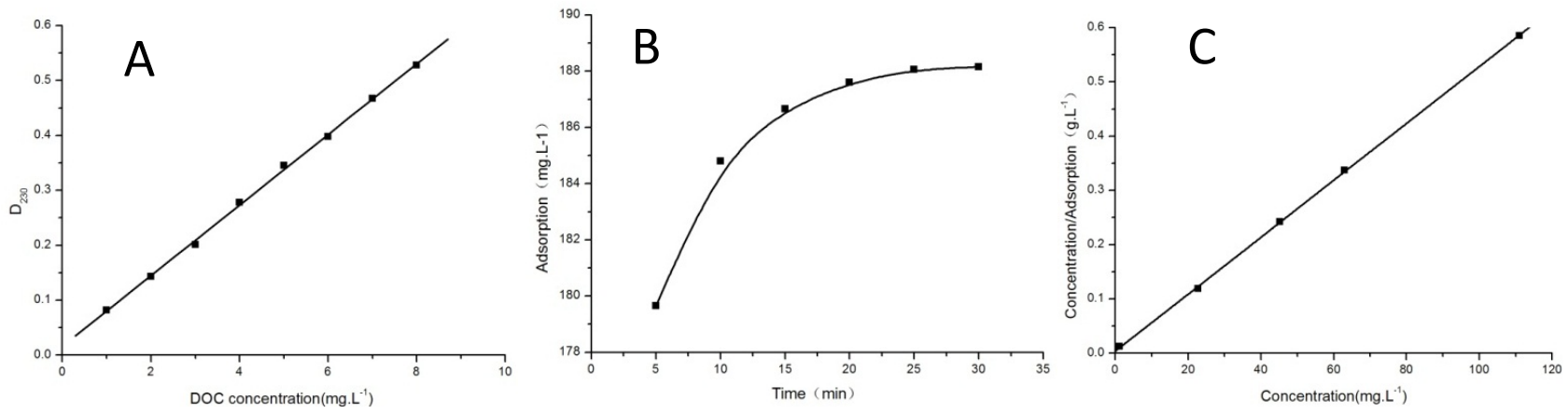

Fig. 2 ACNP-DOC drug delivery system (ACNP-DOC). DOC has the maximum absorption in $230 \mathrm{~nm}$ by ultraviolet and visible spectrophotometer. In the concentration range of $1 \sim 8 \mathrm{mg} / \mathrm{L}$, the absorbance D of DOC and the concentration $\mathrm{C}$ of DOC had a linear positive correlation, satisfying the linear regression equation $\mathrm{D}=0.00412+0.06429 \mathrm{C}(\mathrm{r}=0.99952, \mathrm{P}<0.0001)(\mathrm{A})$; ACNP reached to the balance state of absorbing DOC about 25 min (B); The adsorption isotherm equations was $\mathrm{C} / \mathrm{X}=-0.00405+0.00511 \mathrm{C}(\mathrm{r}=0.99991, \mathrm{P}<0.0001)$, and the saturated adsorption quantity of ACNP for DOC: $\mathrm{Xm}=195.69 \mathrm{mg} / \mathrm{g}$ at mass ratio of ACNP: DOC $=5: 1(\mathrm{C})$.

The adsorption isotherm equations was $\mathrm{C} / \mathrm{X}=-0.00405$ $+0.00511 \mathrm{C}(\mathrm{r}=0.99991, \mathrm{P}<0.0001)$, and the saturated adsorption quantity of ACNP for DOC: Xm $=195.69 \mathrm{mg} /$ $\mathrm{g}$ at mass ratio of $\mathrm{ACNP}$ : $\mathrm{DOC}=5: 1$ (Fig. $2 \mathrm{C}$ ).

\subsection{The behavior of ACNP in the medium.}

Under LM, A549 cells look like polygon in morphology (Fig. 3A). In the blank medium without cells, ACNP evenly adhered to the bottom of culture dish. In the blank ACNP control group of cell cultures, ACNP distributed mainly around the cells and the surfaces of the cells (black arrow in Fig. 3B), although some of them evenly distributed in the bottom of the culture dish. The cells all lived in good condition and there were no significant changes in morphology. In DOC treated groups, the cells had various abnormal changes including spherical and smaller bodies and detachment from the wall. These morphological changes became more and more obvious with the increment of DOC concentrations, indicating the cells were damaged by DOC (Fig. 3C). In ACNP-DOC treated groups, the cells had more obvious morphological changes (black arrows in Fig. 3D) than those treated with DOC especially in the cells with ACNP around them, indicating ACNP improvement of the effects of DOC.
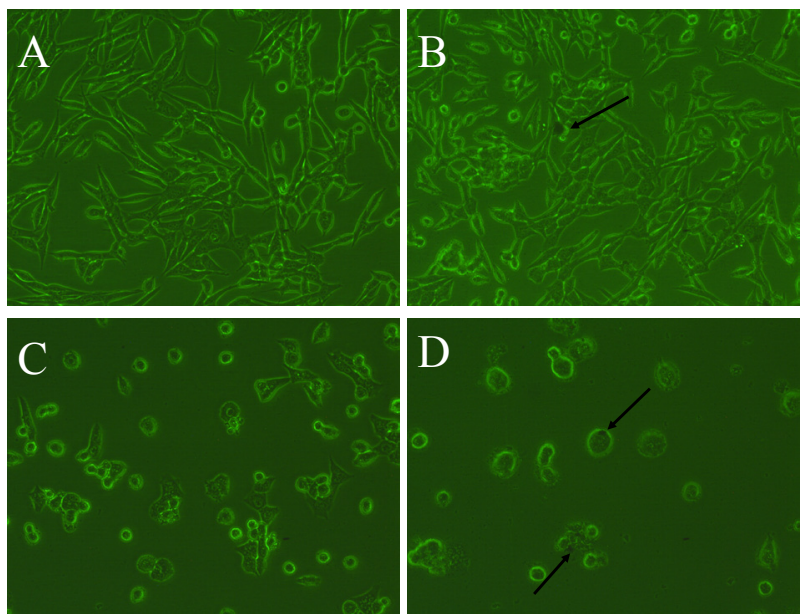

Fig. 3 The behavior of ACNP in the medium under LM. A: Control group; B: ACNP group; C: DOC group; D: ACNP-DOC group. Black arrows show the ACNP distributed mainly around the cells and the surfaces of the cells.

Nano Biomed. Eng. 2013, 5(2),94-101

\subsection{The influence of drugs on A549 cells under TEM.}

Under TEM, The control cell membranes and nuclear membranes were complete and outline was clear. The heteromatin was well distributed in nuclears and the nucleolus was big and clear. There was none of particles in abnormal cells. The subcellular strucutres, including mitochondria, lysosome and endoplasmic reticulum were normal in shape (Fig. 4A). After the cells were treated with ACNP for $4 \mathrm{~h}$, the membranes and nuclear membranes were as complete as that seen in control group with exception of some black ACNP in nuclear and nucleolus (black arrows in Fig. 4B). The cells treated with DOC for $4 \mathrm{~h}$ exhibited morphological characteristics of apoptosis including condensation of the cytoplasm, condensation and fragmentation of the nuclear chromatin. Mitochondrial had obvious abnormal morphological changes including swelling, cristae decrease or loss (Fig. 4C). In ACNP-DOC treated groups, apoptotic characteristics can be seen in more A549 cells and the appearance of morphological changes were more obvious
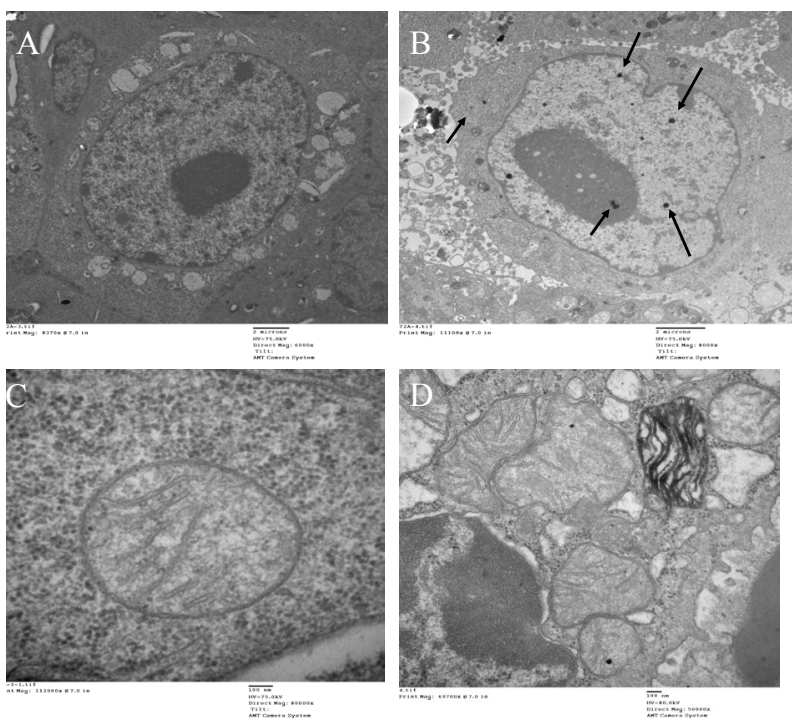

Fig. 4 The influence of drugs on A549 cells under TEM. A: Control group; B: ACNP group; C: DOC group; D: ACNP-DOC group. 
http://nanobe.org
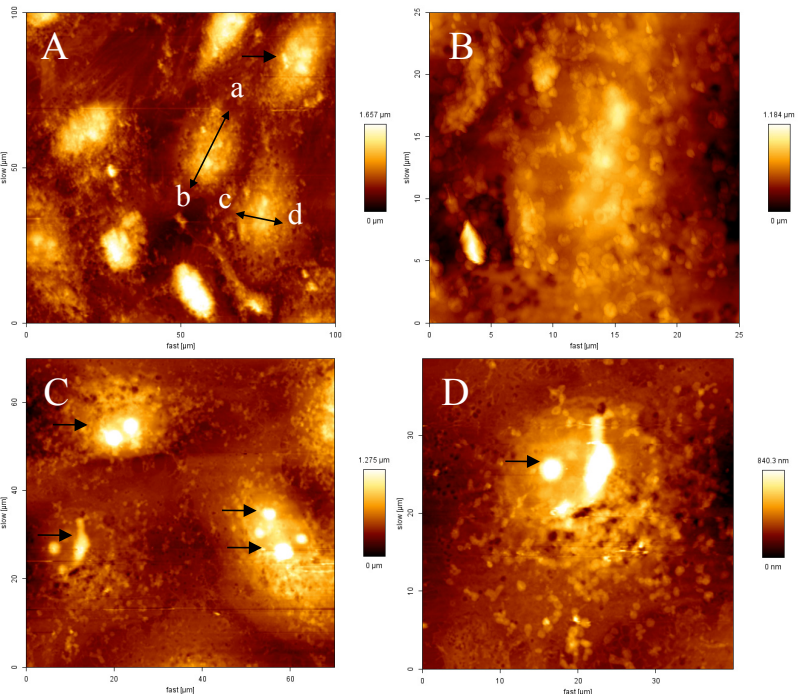

Fig. 5 AFM images of A549 cells. A: Control group; B: The enlarged view of A; C: ACNP-treated A549 cells; D: The enlarged view of C. "a $\leftrightarrow b$ " is the length of the cell body. "c $\leftrightarrow$ d" is the width of the cell body. Black arrows show the outstanding particles of cells.

in comparison with DOC treated. ACNP can be seen in the damaged cells and deformed mitochondria (Fig. 4D).

\subsection{The influence of drugs on A549 cells under AFM}

Under AFM, the control A549 cells presented spindlelike, with a length of $49 \pm 7 \mu \mathrm{m}$ (a to b in Fig. 5 A), a width of $32 \pm 6 \mu \mathrm{m}$ (c to $d$ in Fig. $5 \mathrm{~A}$ ) and a height of $1 \pm$ $0.3 \mu \mathrm{m}$. There were 3 4 outstanding particles measured as $25 \pm 5 \mathrm{~nm}$ in the central disc-like basin (black arrow in Fig.5A, B). The surface of the cell bodies is flat with many disc structures in centre and lots of filamentous pseudopodia in peripheral, which may be the shallow skeleton structure. At $4 \mathrm{~h}$ after the addition of drugs, ACNP-treated A549 cells are basically the same as those of the control cells (Fig. 5C, D).

Fig. 6 shows the AFM scanning image of A549 cells treated with drugs. Column DOC listed the AFM image of A549 cells acted by different concentrations of DOC for $4 \mathrm{~h}$. Column ACNP-DOC listed the A549 cells acted by different concentrations of ACNP-DOC for $4 \mathrm{~h}$. The figure shows the ACNP-DOC treated cells had more serious damage than those treated with DOC. DOC-treated cells produced some holes and formed "honeycomb" structure in their membranes (black arrow in Fig. 6 column DOC), losing their flat and disc structures. The number of these abnormal structures was in dose-dependent. At the concentration $0.8 \mu \mathrm{g} / \mathrm{ml}$, the cell membrane of DOC-treated cells begins to develop "honeycomb" structure. At the concentration of 20-100 $\mu \mathrm{g} / \mathrm{ml}$, "honeycomb" structure of cell membrane is more common. ACNP-DOC treated cells had more rough membranes and produced more holes than DOC treated cells and there was also a dose-effect relation between these abnormal structures and ACNP-DOC treatment. The above AFM morphological characteristics hint that both DOC and ACNP-DOC affect the cell membrane integrity, but ACNP-DOC are more effective than DOC. Except the above morphological characteristics, there had some new abnormal structures in ACNP-DOC treated cells. At concentration of $0.8 \mu \mathrm{g} / \mathrm{ml}$, cell bodies became concave at the convex edge of disk just like "red blood cells" (black arrow in Fig. 6 column ACNP-DOC). These disc structures independently distributed, extruding the surface of the cell membrane and connected with each other through a kind of cable structures. At concentration $4.0 \mu \mathrm{g} / \mathrm{ml}$, more disc structures gathered into "group" and there were wheel-arm-like filaments in the bottom of the disc (black rectangle in Fig. 6 column ACNP-DOC). At concentration of $20-100 \mu \mathrm{g} / \mathrm{ml}$, the disc structure disappears and the cell membrane appears unequal size holes (red arrow in Fig. 6 column ACNP-DOC), the rough membranes were covered with gathered or dispersed particle materials (green arrow in Fig. 6 column ACNP-DOC). These particles had diameters of $233 \pm 20 \mathrm{~nm}$. According to the particle size and morphology in combination with the LM observation of the ACNP behavior in culture medium, it was inferred that these particles are ACNP-DOC particles. Because DOC is a drug that influence the metabolism of the micro-
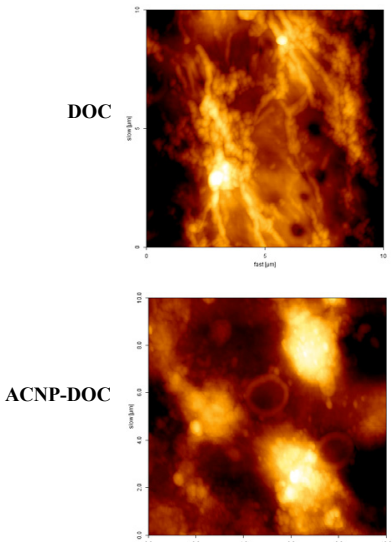

$0.16 \mu \mathrm{g} / \mathrm{ml}$
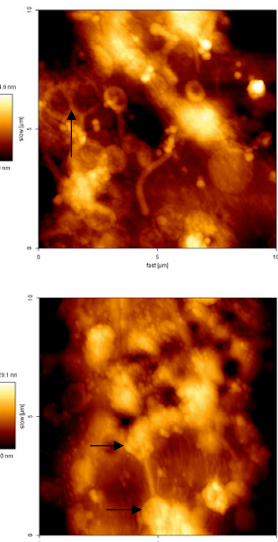

$0.8 \mu \mathrm{g} / \mathrm{ml}$
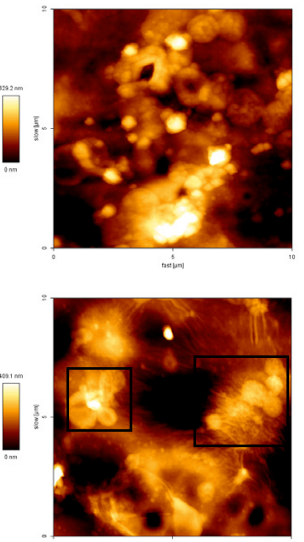

$4 \mu \mathrm{g} / \mathrm{ml}$
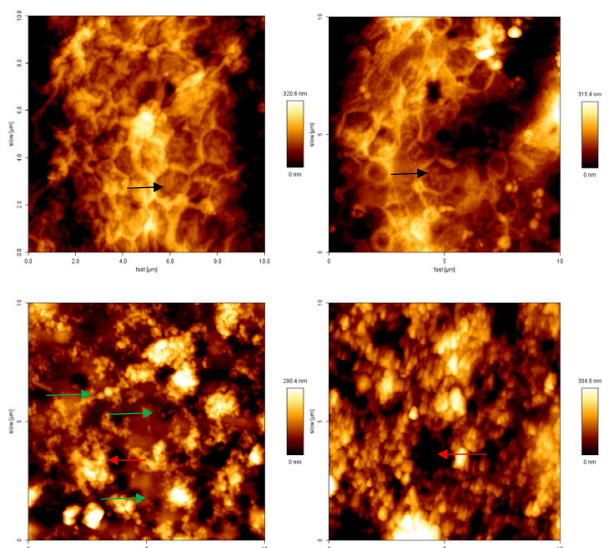

$20 \mu \mathrm{g} / \mathrm{ml}$

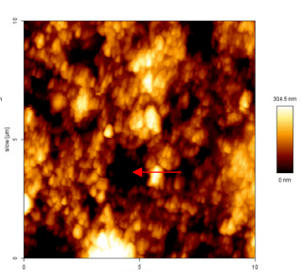

$100 \mu \mathrm{g} / \mathrm{ml}$

Fig. 6 AFM images of DOC-treated and ACNP-DOC treated A549 cells. Column DOC listed the AFM image of A549 cells acted by different concentrations of DOC for $4 \mathrm{~h}$. Black arrow shows the "honeycomb" structure in column DOC. Column ACNP-DOC listed the A549 cells acted by different concentrations of ACNP-DOC for $4 \mathrm{~h}$. Black arrow shows the "red blood cells", black rectangle shows the group of the "red blood cells", red arrow shows the holes and green arrow shows ACNP. 
tubes that keep the cell in normal morphology, these abnormal cell structures in the membranes were related to the cell skeleton changes resulted from the effect of DOC. In ACNP-DOC, ACNP is carriers while DOC is effect components but ACNP improved the effects of DOC.

\subsection{The inhibitory effects of ACNP-DOC on the proliferation of A549 cells}

The results of the MTT assay showed that ACNP had no significant inhibitory effects on A549 cells. At 12, 24, 48 and $72 \mathrm{~h}$ after the addition of drugs, Both DOC and ACNP-DOC significantly inhibited the proliferation of A549 cells in dose- and time-dependent manners. At $12,24,48$ and $72 \mathrm{~h}$ after addition the $50 \%$ inhibitory concentrations (IC50) of ACNP-DOC were 2.57, 0.24, 0.15 and $0.05 \mu \mathrm{g} / \mathrm{ml}$, respectively, significantly smaller than those of DOC, which were 99.42, 34.76, 9.08 and $0.99 \mu \mathrm{g} / \mathrm{ml}$ respectively (Fig. 7).

\section{Discussion}

ACNP is a matter of porous particle with a broad absorption spectrum. It is easy to put chemical particles such as drugs in the micro holes of ACNP relying on the adsorption characteristic. ACNP as a cancer drug carrier has special characteristics in the releasing of the drugs they carry. ACNP adsorbs chemical particles generally by physical interactions and no covalent bond to form between ACNP and adsorbed matters, so that, the adsorbed drugs can easily disintegrate out from the surface of ACNP again, becoming free drug
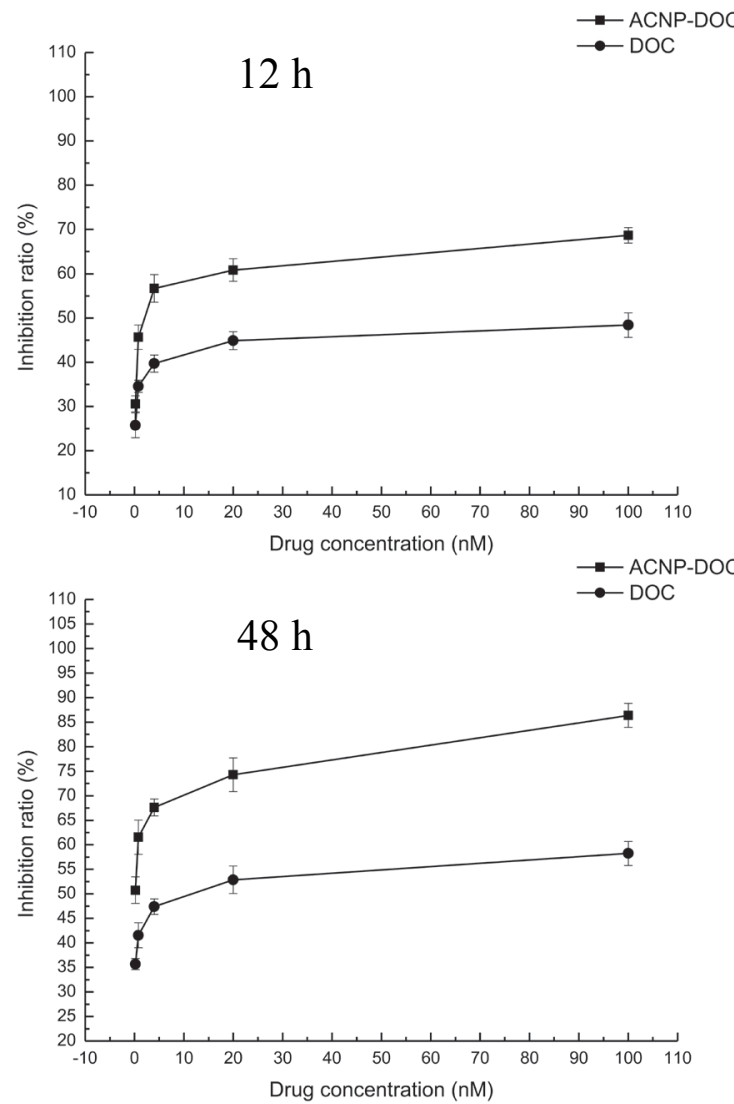

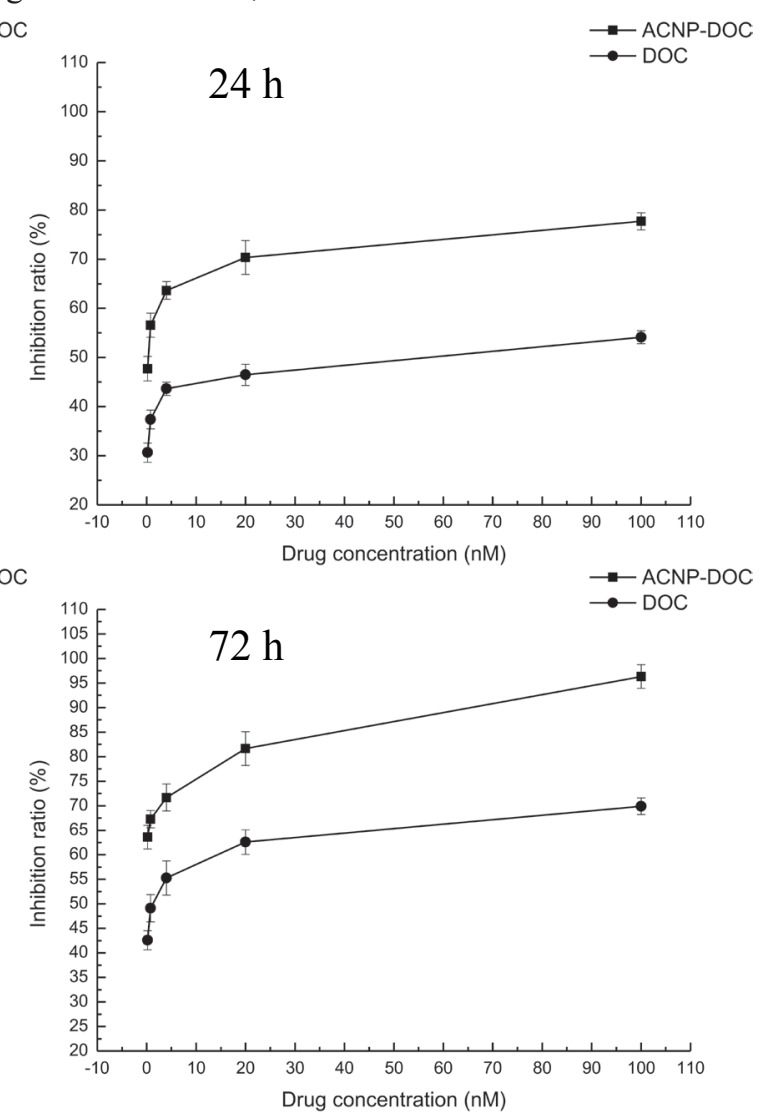

particles. An outstanding property of ACNP is that the drug concentration around the carriers is in the dynamic balance with the quantity of the drugs loaded on them and can be correctly calculated in mathematical equation as that obtained from our experiments. Thus, it is very favorable to maintain the drug concentration of local organizations in body through the controlling of drug-loading during preparation. The DOC adsorbed on the ACNP has such strong damage to cancer cells because ACNP-DOC releases DOC to the surrounding environment to injure them. The ACNP-DOC effect's range is from $0.8 \sim 200 \mu \mathrm{g} / \mathrm{ml}$, the released chemical molecules temporarily accumulated around the carrier particles, making it possible to keep the concentration of drugs being largest in around, so the damage has "local characteristics". The diameter of the ACNP is smaller, the specific surface area is bigger, and the adsorption ability is stronger $[18,19]$, making them capable of effect transporting drugs without significant loss in the way from administration sites to the therapeutic related sites.

DOC is a drug that influences the decomposition of micro-tubes that constitute the skeleton to keep the cells in normal morphology. The abnormal metabolism of micro-tubes definitely results in abnormal cell skeleton, leading to the surface morphological changes of cells, which is very suitable for AFM measurements that relying on the surface scanning by a tip immobilized on a cantilever. AFM observation revealed "disc" and "honeycomb" in the membranes of DOC and ACNP-DOC treated cells, which well reflects the abnormal changes in

Fig. 7 The inhibitory effects of DOC and ACNP-DOC on the proliferation of A549 cells. $(\mathrm{p}<0.05, \mathrm{n}=5)$ 
microstructures and the eruption of the cell membranes. These surface pathological observations can't be realized by other instruments.

There is no obvious change in shape, size and height of the cells between training ACNP and A549 cells together for $4 \mathrm{~h}$ and A549 single [15-17]. We can preliminary be sure that the damage to the cells has nothing to do with ACNP at the several time points. With the increasing of the concentration of drugs, the extent of damage of ACNP-DOC is always greater than DOC. Cell membrane is barrier from outside environment, and is the interface of inside and outside of the communication, and is very important in its life. Many researches show that cell membrane change is one of the early cell damage performances. The change of the membrane structure and function impact on the cell's normal functions directly. Therefore, the research of the membrane surface structure is extremely important on the level from nanometer to micron grade. AFM scanning is a force microscope (Scanning force microscopy, SFM) with the highest resolution, is used broadly, and can achieve the atomistic level. The results demonstrated that AFM is a useful tool to study the subcellular morphology of cultured A549 cells. Although the resolution cannot get theoretical atomic or molecular level for biological samples, the resolution of AFM is high enough for the satisfactory observation of the nanometer morphology an fine structures of cells.AFM beyond the resolution limitation of the wavelength and electric microscope, and be able to capture very weak interaction information between atom and atomic sample by a small probe tip. Firstly, AFM had a widely suitable size range, which may be from the entire cell body of the cells of several tens of micrometers to the fine structures of only several nanometers. Secondly, AFM can directly study on the surface of the cell membranes without the need for plating a layer of the high electrondensity materials, which is the special feature of AFM, unable to be substituted by other instruments. Thirdly, AFM image itself is three-dimensional, not like TEM, which only can obtain three-dimensional figures by adding the plane images of the ultrathin sections of the samples. The last one is AFM convenience in operation and the sample preparation. Therefore, we can reveal the problem of the cell membrane structure according to the change of the cell membrane surface [20].

Now thinking, ACNP itself does not react with the body's tissues or cells. But, it can change its carrying drugs or chemical molecule distribution in body, strengthening the chemical and physical efficacy of drugs, reducing the harmful side effects. Our results including that of TEM, AFM and MTT experiments demonstrated that ACNP-DOC are more effective to kill A549 cells than free DOC but blank ACNP had no effect on the cells, indicating that the improvement of the effects of DOC in ACNP-DOC delivery system is resulted by strengthening effects of ACNP, as a drug carrier, on the effects of DOC. In ACNP-DOC drug delivery system, the strengthened effects developed from the carrier properties 100 OentosT of ACNP rather than the plus of the effects of ACNP and DOC. The mechanism for these strengthening effects may be explained from several factors. LM observation revealed that ACNP had special affinity for A549 cells, which made them accumulated around the cells and on the cell membranes, where the drugs they carried were released. This selective distribution of ACNP improved the concentration in the microenvironment that directly contacts the cell, which allowed more drug molecules to act on the cells. TEM revealed that ACNP enter the cells, this property allowed more DOC molecules to interact with micro tubes. AFM observations provided more detail information about the cell membrane damage such as the disc and honeycomb structures. For the mechanism of ACNP to strengthen the effects of DOC, AFM revealed that DOC-treated cells had no obvious "cable-like structures", which meant the loss of their function to form cell skeleton. ACNP-DOC made this phenomenon aggravated without changes in the way of DOC action.

\section{Conclusions}

In this study, we build the drug delivery system of ACNP-DOC and researched the effects of it on A549 human lung cancer cells. ACNP-DOC was more effective to kill A549 cells than free DOC and ACNP could strengthen the chemical and physical efficacy of DOC by carrying drugs to the microenvironment of the cells and into the cells and cell nuclear, indicating ACNP could serve as a good nanocarrier for anti-cancer drug delivery to target cells and have a great potential application in antitumor chemotherapy. AFM could be a useful tool to be applied in the research of pathology and pharmacology to observe cell membranes. The mechanism behind the efficacy of ACNP-DOC in vivo should be further studied.

\section{Acknowledgements}

This work was supported by the budget of China 973 project (2010CB933904) and State Project for Essential Drug Research and Development of China (2011ZX09102-001-15).

\section{References}

1 Zeng Z.B. The clinical app lication of actived carbon. Pract Clin Med. 2004. 5 (2):139 -140.

2 Hagiwara A., Takahashi T., Ueda T., Lee R., Takeda M., Itoh T. Intraoperative chemotherapy with carbon particles adsorbing mitomycin $\mathrm{C}$ for gastric cancer with peritoneal dissemination in rabbits. Surgery. 1988. 104(5):874-881.

3 Qu Q.L., Zhang Y.G., Yang L.Z., Sun L. Intraperitoneal chemotherapy with mitomycin $\mathrm{C}$ bound to activated carbon nanoparticles for nude mice bearing human gastric carcinoma. Chin J Oncol. 2006. 28(4):257-260.

4 Kam N.W., O’Connell M., Wisdom J.A., Dai H. Carbon nanotubes as multi-functional biological transporters and near-infrared agents for selective cancer cell destruction. Proc Nail Acad Sci USA. 2005. 102(33):11600-11605.

5 Tongeren M.J., Kromhout H., Gardiner K. Trends in levels of inhalable dust exposure, exceedance and overexposure in the European carbon black manufacturing industry. Ann Occup Hyg. 2000. 44(4):271-280.

6 Zhang Y.D. Nanobiotechnology. Beijing: Science Press. 2005. 1.

7 Yang Z., Zhao J.X., Li P.F., Zhang Y.G. Effects of activated carbon nanoparticles on anti cancer effect of 5-Fu. Bull Acad Mil Med Sci. 2009. 33(5):416-420. 
8 Zhang H., Sun L., Zhang Y.G. Intraperitoneal chemotherapy with mitomycin $\mathrm{C}$ bound to activated carbon nanoparticles using bioluminescence imaging technology. Mil Med Sci. 2011, 35(4): 299-302.

9 Feazell R. P., Nakayama-Ratchford N., Dai H., Lippard S.J. Soluble single-walled carbon nanotubes as longboat delivery systems for platinum(IV) anticancer drug design. J. Am.Chem. Soc. 2007, 129 (27): 8438-8439.

10 Zhu Y. H., Peng A. T., Carpenter K., Maguire J.A., Hosmane N.S., Takagaki M. Substituted carborane-appended water-soluble singlewall carbon nanotubes: new approach to boron neutron capture therapy drug delivery. J. Am. Chem. Soc. 2005, 127 (27):9875-9880.

11 Zhang Z., Yang X., Zhang Y., Zeng B., Wang S., Zhu T., Roden R.B., Chen Y., Yang R. Delivery of telomerase reverse transcriptase small interfering RNA in complex with positively charged single-walled carbon nanotubes suppresses tumor growth. Clin. Cancer Res. 2006, 12(16):4933-4939.

12 Kam N. W., O’Connell M., Wisdom J. A., Dai H. Proc. Natl. Carbon nanotubes as multifunctional biological transporters and near-infrared agents for selective cancer cell destruction. Acad. Sci. USA 2005, 102 (33):11600-11605.

13 Pantarotto D., Briand J. P., Prato M., Bianco A. Translocation of bioactive peptides across cell membranes by carbon nanotubes. Chem. Commun (Camb) .2004, 10 (1):16-17.

14 Kateb B., Van Handel M., Zhang L., Bronikowski M.J., Manohara H., Badie B. Internalization of MWCNTs by microglia: possible application in immunotherapy of brain tumors. NeuroImage
2007, 37(Suppl 1): S9-S17.

15 Zhang Y.G. Nanotoxicology . Beijing: Peking union medical college press, 2010:256-265

16 Huang G.J., Chen Z.G., Liu Y., Qian L.P., Chen J., Ni Q.X., Zhang Y.L. Guidance of activated carbon nanoparticles in gastric cancer lymphadenectomy. China Journal of Modern Medicin 2005, 15(2):233-237.

17 Chen H., Huang G.J., Ni Q.X., Zhang Y.L. The application of nanometric activated carbon particles in the intralymphatic chemotherapy as a drug carrier. Fudan Univ. J. Med. Sci. 2007, 34(4):518-521.

18 Stearns R.C., Paulauskis J.D., Godleski J.J. Endocytosis of Ul trafine particles by A549 cells. Am. J. Respir. Cell Mol. Biol. 2001, 24(2):108-115.

19 Bitterle E., Karg E., Schroeppel A., Kreyling W.G., Tippe A., Ferron G.A., Schmid O., Heyder J., Maier K.L., Hofer T.Dosecontrolled exposure of A549 epithelial cells at the air-liquid interface to air borne ultrafine carbon aceous particles. Chemosphere. 2006, 65(10):1784-1790.

20 Sayes C.M., Wahi R., Kurian P.A., Liu Y, West J.L., Ausman K.D., Warheit D.B., Colvin V.L . Correlating nanoscale titania structure with toxicity: A cytotoxicity and inflammatory response study with human dermal fibroblasts and human lung epithelial cells. Toxicol. Sci. 2006, 92 (1):174-185.

Copyright:(c) 2013 S. Lan et al. This is an open-access article distributed under the terms of the Creative Commons Attribution License, which permits unrestricted use, distribution, and reproduction in any medium, provided the original author and source are credited. 